\title{
AC 2007-704: THE CALIFORNIA REGIONAL CONSORTIUM FOR ENGINEERING ADVANCES IN TECHNOLOGICAL EDUCATION (NSF ATE REGIONAL CENTER CREATE)
}

\section{Sharlene Katz, California State University-Northridge}

Sharlene Katz is Professor in the Department of Electrical and Computer Engineering at California State University, Northridge (CSUN) where she has been for over 25 years. She graduated from the University of California, Los Angeles with B.S. (1975), M.S. (1976), and Ph.D. (1986) degrees in Electrical Engineering. Recently, her areas of research interest have been in engineering education techniques and neural networks. Dr. Katz is a licensed professional engineer in the state of California.

\section{Kathleen Alfano, College of the Canyons}

Kathleen Alfano is Director/Principal Investigator of the California Regional Consortium for Engineering Advances in Technological Education (CREATE), an NSF ATE Regional Center for Information and Manufacturing Technology. She graduated from Chestnut Hill College with a B.S. in Chemistry (1976), Purdue University with a M.S. in Education (1981), and the University of California, Los Angeles with a Ph.D. in Higher Education, Work and Adult Development (1993). Dr. Alfano has been on the faculty at College of the Canyons since 1996. 


\section{The California Regional Consortium for Engineering Advances in Technological Education (NSF ATE Regional Center CREATE)}

\section{Background}

The California Regional Consortium for Engineering Advances in Technological Education CREATE Regional Center is a joint effort between community colleges, universities, and hightech engineering technology employers. Together the consortium members serve over 9,000 square miles of coastal and central California. This area served by the members represents a population of over one million. The Center is funded by the National Science Foundation's (NSF) Advanced Technological Education (ATE) program, which is designed to strengthen the preparation of technicians for the high performance workplace of advanced technologies. The Center's goal is to address the needs of industry by producing, as a multi-county consortium, highly skilled and educated technicians to better meet national and State workforce demands in the engineering technology fields. The CREATE-ATE Regional Center focuses on utilizing a multi-college consortium to develop better approaches to faculty development, in pedagogy and content; industry partnership for improvement of curricula; $2+2$ B.S. program development and articulation; and improving assessment.

The consortium includes six community colleges in the region: Allan Hancock College, College of the Canyons, Cuesta College, Moorpark College, Oxnard College, and Santa Barbara City College. Additionally, the center works with a number of the California State Universities on projects ranging from experimental delivery modes, new $2+2$ program development and articulation.

CREATE was previously funded by two NSF-ATE projects, which met or exceeded all of their objectives. The project had four primary goals, which included curriculum development, enrollment and retention, work-based site experiences, and professional development. The CREATE consortium developed programs that began with a common core curriculum in either engineering technology or computer networking. The common core curriculum allowed students to transfer from a participating college to any college in the consortium to take classes in any of the specialty areas offered by the consortium campuses. The collaborative effort between community colleges, universities, and employers has resulted in a strong regional consortium.

This paper summarizes the objectives and accomplishments of the CREATE Center over the past year. Previous years' accomplishments are described in Reference 1.

\section{CREATE Center Objectives and Accomplishments}

The CREATE Center, which evolved out of Project CREATE's successes, established objectives, activities, outcomes, and timelines designed to target five chief areas of need or goals that the CREATE project identified. These objectives along with the primary accomplishments of the past year are given below. 
Objective 1: Improve pedagogical skills of faculty in all areas of NSF ATE technical areas through teacher training.

- In previous years [1], an award-winning training program was adapted to train part-time teachers without teaching backgrounds to be pedagogically strong. In the period from program inception to the last reported data at ASEE's annual conference in 2006, 22 faculty were trained as Teaching Facilitators, representing 14 community colleges. During the past year 29 more faculty have completed this training representing an additional 17 new community colleges from over ten States. Additionally, the implementation of the train the trainer model has accelerated in the last year. In the last reported data, 42 full and part-time faculty had completed Teaching Skills Workshop. In the past year, 37 more have completed and an additional 48 faculty are scheduled to complete by June of 2007 .

- CREATE faculty have continued to work with other faculty inside and outside of the consortium to broaden their technical background in the manufacturing and information technology areas. Two CREATE faculty members completed the second level of BICSI (cabling certification) instructor training and hosted an intensive week of training and testing for four faculty members from three of the CREATE community colleges. A CREATE faculty member is mentoring other CREATE faculty from five colleges in Electronics and has conducted individual and group workshops. Another CREATE faculty member conducted free IT Essentials and Security workshops for faculty from eight other colleges and agencies.

Objective 2: Improve articulation of $2+2+2$ pathways in the fields of Information Technology and Manufacturing Technology

- The CREATE Center continues to work with its community college faculty to have their courses approved for transfer. Over the past four years 153 CREATE technology courses have been approved for California State University system transfer.

- In Fall 2005, California State University, Channel Islands began to offer the new CREATE-sponsored in-person/on-line hybrid 2+2 B.S. Program in Information Technology program. The students in this program are making impressive progress with excellent reports from both students and faculty on the program.

- Students in the California State University, Fresno Industrial Technology online/hybrid program continue to graduate.

- CREATE has begun articulating requirements for the B.S. in Manufacturing Technology at California State University, Long Beach and the B.S. in Industrial Technology at California Polytechnic State University, San Luis Obispo so that interested community college students can make a smooth transition to the four year program.

- Three of the CREATE community colleges have produced marketing materials to improve student recruitment into their programs.

- Currently working with the NSF ATE Midwest Center to adapt their marketing materials.

Objective 3: Implement regional programs in Information Technology, Engineering Technology and Manufacturing Technology that reflect existing and emerging industry needs. 
- CREATE has developed and implemented over 50 new engineering/manufacturing/ electronics/information technology Associate degree and certificate programs. These new curricula have resulted in 197 new or revised courses being taught at six community colleges in Fall of 2006 that integrate academic and vocational subject matter with industry skill standards and/or competencies. Additionally, in Spring of 2007 two new degree programs have won approval and will give new transfer options in Information Technology (Cuesta College) and Mechatronics (Allan Hancock).

- CREATE conducted a comprehensive review of the region's skills needs and crossmapped these needs to the embedded technical and soft skills currently being taught at each of the CREATE colleges.

- A new Mechatronics degree program was developed and implemented at Allan Hancock College.

- A feasibility study to determine the need for a new 4-year B.S. in Engineering Technology degree to be offered in the region.

Objective 4: Develop and implement a model assessment plan to measure longitudinally the success of the educational experience.

- Continuing studies have shown that since CREATE's initial NSF funding in 1999-2000, over 20,000 students have taken at least one CREATE credit course and over 3,000 have successfully completed degrees.

- A rigorous pre and post assessment of faculty changes in practice and in student learning related to the teaching workshops was piloted in 2005-2006 and a full study is being conducted in 2006-2007 in cooperation with Cisco Systems.

Objective 5: Develop and implement a plan to sustain and institutionalize CREATE partnerships and models.

- Part of the sustainability plan for the CREATE Center is its role as one of 17 Cisco Academy Training Centers (CATCs) nationally. CREATE acts as a mentor and training Center for credit, non profit faculty and Regional Academies throughout the Western Region for specific Cisco curricula. Each year CREATE has been asked to increase its scope of training leadership: CCNA (starting 2004); Security and Wireless (2005); IT Essentials (2006). Cisco provides monetary support to the CREATE Center.

- CREATE serves as a Model Partnership within the State and nationally: CREATE mentors groups of colleges and high schools who seek to develop partnerships with industry and each other to enhance occupational education. Colleges and high schools/districts such as Portland Community College, the Bay Area Cooperative, and LAUSD are among the groups that CREATE is currently mentoring. 


\section{$\underline{\text { Summary }}$}

The CREATE consortium, a joint effort between community colleges, universities and high-tech engineering technology employers is current in its eleventh year of operation. This paper highlights the accomplishments of the past year (2005/2006) as an NSF ATE Regional Center. Through its programs and commitment to partnerships, the CREATE consortium has had a significant impact on students, faculty and colleges in its region. The CREATE Center continues to operate in its fifth year as an NSF ATE Regional Center. Further information on CREATE can be found on our website at: http://www.create-california.org.

References

1. Katz, Sharlene and Kathleen Alfano. "California Regional Consortium for Engineering Advances in Technological Education (CREATE),” ASEE 2006 Annual Conference. Chicago, Illinois. June 2006. 